\title{
Fenologia, cultivo in vitro e aclimatização da bromélia ameaçada de extinção Nidularium minutum Mez
}

\author{
Flávia Maria Kazue Kurita \\ Bárbara de Mello Machado \\ Nathália Bernardes Teixeira \\ Camilla Gomes de Abreu César \\ Catarina Carvalho Nievola \\ Vívian Tamaki * \\ Instituto de Botânica, Núcleo de Pesquisa em Plantas Ornamentais \\ Caixa Postal 68041, CEP 04045-972, São Paulo $\square$ SP, Brasil \\ * Autor para correspondência \\ vtamaki@gmail.com
}

Submetido em 15/05/2013

Aceito para publicação em 18/12/2013

\section{Resumo}

O conhecimento da fenologia de uma espécie indica o período mais favorável à coleta de sementes maduras, que podem ser utilizadas na produção de mudas por meio de métodos eficientes como o cultivo in vitro. Essa técnica tem sido considerada uma estratégia para a propagação de espécies ameaçadas de extinção, como é o caso da bromélia Nidularium minutum Mez. Este artigo teve por objetivo identificar a época de frutificação e de produção de sementes de exemplares in situ de $N$. minutum e estabelecer um protocolo de cultivo in vitro a partir de sementes. A fenologia da espécie foi acompanhada por 12 meses em plantas na Estação Biológica do Alto da Serra, em Paranapiacaba-SP. Os resultados mostraram que o melhor período para a colheita das sementes foi de junho a agosto de 2008. O processo germinativo ocorreu em todas as temperaturas testadas, tendo sido mais eficiente aos $26^{\circ} \mathrm{C}$, não sendo necessários sais minerais. As melhores condições para o crescimento das plantas ocorreram com a mesma temperatura, em meio Murashige e Skoog (MS) contendo metade da concentração dos macronutrientes. Por meio desse protocolo, é possível conservar as plantas in vitro e otimizar sua produção para o uso em programas de repovoamento.

Palavras-chave: Bromeliaceae; Germinação; Micropropagação; Sementes; Temperatura

\section{Abstract}

Phenology, in vitro cultivation, and acclimatization of the endangered bromeliad species Nidularium minutum Mez. Knowledge on the phenology of a species indicates the most favorable period to harvest mature seeds, which may be used for producing seedlings through effective methods as in vitro cultivation. This technique has been regarded as a strategy for the propagation of endangered species, such as the bromeliad species Nidularium minutum Mez. This article aimed at identifying the time of fructification and seed production of in situ specimens of N. minutum and establishing a protocol of in vitro cultivation through seeds. The species 
phenology was followed up for 12 months in plants at the Alto da Serra Biological Station, in Paranapiacaba, São Paulo, Brazil. The results showed that the best time to harvest seeds was from June to August 2008. The germination process occurred at all temperatures tested, being more effective at $26^{\circ} \mathrm{C}$, with no need of mineral nutrients. The best conditions for growing plants occurred with the same temperature, with Murashige and Skoog (MS) medium containing half the macronutrient concentration. By means of this protocol, it is possible to preserve in vitro plants and optimize their production to be used in restocking programs.

Key words: Bromeliaceae; Germination; Micropropagation; Seeds; Temperature

\section{Introdução}

Bromeliaceae compreende 58 gêneros e 3.248 espécies (LUTHER, 2010) sendo que muitos de seus representantes são considerados ameaçados de extinção (PENCE, 2011). Dentre as razões para este fato está a destruição dos habitats devido ao crescente desmatamento, como ocorre na Mata Atlântica, que é considerada um hotspot (MYERS et al., 2000). Segundo Sugiyama (2010), esse bioma possui elevado índice de endemismo com diversas espécies ameaçadas de extinção, como é o caso da bromélia Nidularium minutum Mez, endêmica da Serra de Paranapiacaba, localizada no Estado de São Paulo, região da Mata Atlântica, local cujas temperaturas variam de 2 a $30^{\circ} \mathrm{C}$ (GUTJAHR; TAVARES, 2009). Essa espécie é considerada vulnerável conforme publicado no Livro Vermelho das Espécies Vegetais Ameaçadas de Extinção (MAMEDE et al., 2007).

Nidularium minutum apresenta hábito terrícola. Sua altura varia entre 30 a $40 \mathrm{~cm}$, sendo que as folhas são suberetas com textura fina e margens serrilhadas. As brácteas primárias apresentam cor verde da parte basal até a metade e vermelha da metade até a parte apical. As flores são brancas, assim como os frutos, e o cálice é verde (WANDERLEY; MARTINS, 2007). Estas características conferem a essa bromélia um expressivo valor como planta ornamental, podendo torná-la alvo do extrativismo, justificando a preocupação com o desenvolvimento de medidas de conservação, como o aumento da eficiência de produção de mudas.

De acordo com Pence (2011), o cultivo in vitro pode ser uma estratégia eficiente para a conservação de plantas, dentre elas as bromélias. O cultivo in vitro realizado a partir de sementes permite que a variabilidade genética da espécie seja mantida, o que é requerido em programas de conservação, sendo considerado alternativo aos bancos de sementes (ENGELMANN, 2010; PENCE, 2011). Exemplos de estudos, que contribuíram para a conservação de bromélias por meio do cultivo in vitro utilizando sementes, foram realizados com as espécies Alcantarea imperialis (Carrière) Harms (MOLLO et al., 2011), Nidularium fulgens Lem. (PAIVA et al., 2009), Vriesea inflata (Wawra) Wawra (PEDROSO et al., 2010), dentre outros.

Em geral, nos trabalhos que visam à produção de bromélias, os explantes são utilizados a partir de plantas matrizes conservadas ex situ. Contudo, quando se deseja utilizar sementes de espécies endêmicas e ameaçadas, como é o caso de $N$. minutum, visitas à campo tornam-se frequentes. Em ambiente natural, N. minutum se propaga, principalmente, por estolhos e, embora na literatura haja relatos sobre a época de floração de $N$. minutum (WANDERLEY; MARTINS, 2007), não há indicações precisas sobre qual o período é o mais favorável para se encontrar o maior número de sementes maduras a serem utilizadas em cultivo. Esse conhecimento pode subsidiar a coleta de sementes de modo racional, durante a época com maior probabilidade de existirem sementes maduras, minimizando os custos de deslocamento à campo.

A obtenção de plantas por meio da germinação in vitro requer a padronização das condições que incluem a seleção da temperatura e composição do meio nutritivo, até a sua transferência para o crescimento em estufa, visando a etapa de aclimatização (KIMBERLY et al., 2003; POMPELLI et al., 2006). De acordo com Goode e Allen (2009), apenas 1\% das sementes da bromélia Aechmea bracteata (Sw.) Griseb. germinam em ambiente natural, sendo que essa porcentagem pode atingir 100\% em condições de temperaturas controladas. Dentre os trabalhos que relatam a influência da temperatura sobre 
a germinação in vitro de bromélias está o de Pompelli et al. (2006), que avaliaram os efeitos desse fator em sementes de Dyckia encholirioides (Gaudichaud) Mez var. encholirioides, e o de Kimberly et al. (2003), que trabalhou com Tillandsia eizii L.B. Sm., sendo que em ambos os trabalhos foram utilizadas faixas de temperaturas próximas aos dos ambientes naturais de ocorrência das espécies em estudo. Não foram encontrados relatos sobre a otimização das condições de germinação in vitro para $N$. minutum.

A maioria dos trabalhos sobre micropropagação de bromélias cita o uso do meio de Murashige e Skoog (1962-MS) com a composição original ou contendo macronutrientes com concentrações reduzidas (TAMAKI et al., 2007), bem como o uso da formulação do meio de Knudson (1946) (FRESCHI et al., 2010). Todavia, tem sido descrito que espécies de bromélias terrícolas podem crescer satisfatoriamente no meio MS original (ARRABAL et al., 2002), embora isso não seja uma regra, pois plantas de abacaxizeiro, apresentaram quantidades de clorofila que indicaram eficiente estado nutricional quando cultivadas em MS com os macronutrientes reduzidos até um quinto da concentração total (TAMAKI et al., 2007).

A etapa seguinte após o estabelecimento do cultivo in vitro é a transferência para condições de crescimento em estufa ex vitro (aclimatização), finalizando a etapa de produção de mudas que poderão ser utilizadas em programas de repovoamento ou disponibilizadas ao mercado de ornamentais.

Este trabalho teve por objetivo identificar o período de produção de sementes em populações naturais de $N$. minutum, visando facilitar a obtenção de explantes e estabelecer um protocolo para germinação de sementes, crescimento in vitro e aclimatização para a espécie.

\section{Material e Métodos}

\section{Estudos fenológicos}

Para acompanhar o desenvolvimento fenológico da espécie foram marcados 21 exemplares, que estavam em estágio inicial de floração (critério utilizado para selecionar os indivíduos), em três populações naturais de Nidularium minutum Mez na Estação Biológica do Alto da Serra de Paranapiacaba, Santo André-SP, Brasil (2346’35,9'S e 46¹8'42,9’W) (Figura 1A), dentre as várias existentes na região.

O acompanhamento foi quinzenal (durante a fase reprodutiva) e mensal (durante a fase vegetativa), no período compreendido entre setembro de 2007 a

FIGURA 1: Nidularium minutum Mez. A. População natural na Estação Biológica do Alto da Serra de Paranapiacaba, Santo André-SP, Brasil. B. Aspecto do indivíduo com as brácteas florais. C. Aspecto geral do fruto. D. Semente. E. Frasco de cultivo in vitro com exemplares de $N$. minutum com seis meses de idade, mantidas a $26^{\circ} \mathrm{C}$ em meio de Murashige e Skoog (1962) contendo a metade da concentração dos sais de macronutrientes, acrescidos de $3 \%$ de sacarose e $0,01 \%$ de myo-inositol . F. Vasos com as plantas aclimatizadas em casa de vegetação. Escala $=0,5 \mathrm{~cm}(\mathrm{c}), 0,025 \mathrm{~cm}(\mathrm{~d}), 1 \mathrm{~cm}$ (e). Fotos: Camila Pereira de Carvalho.
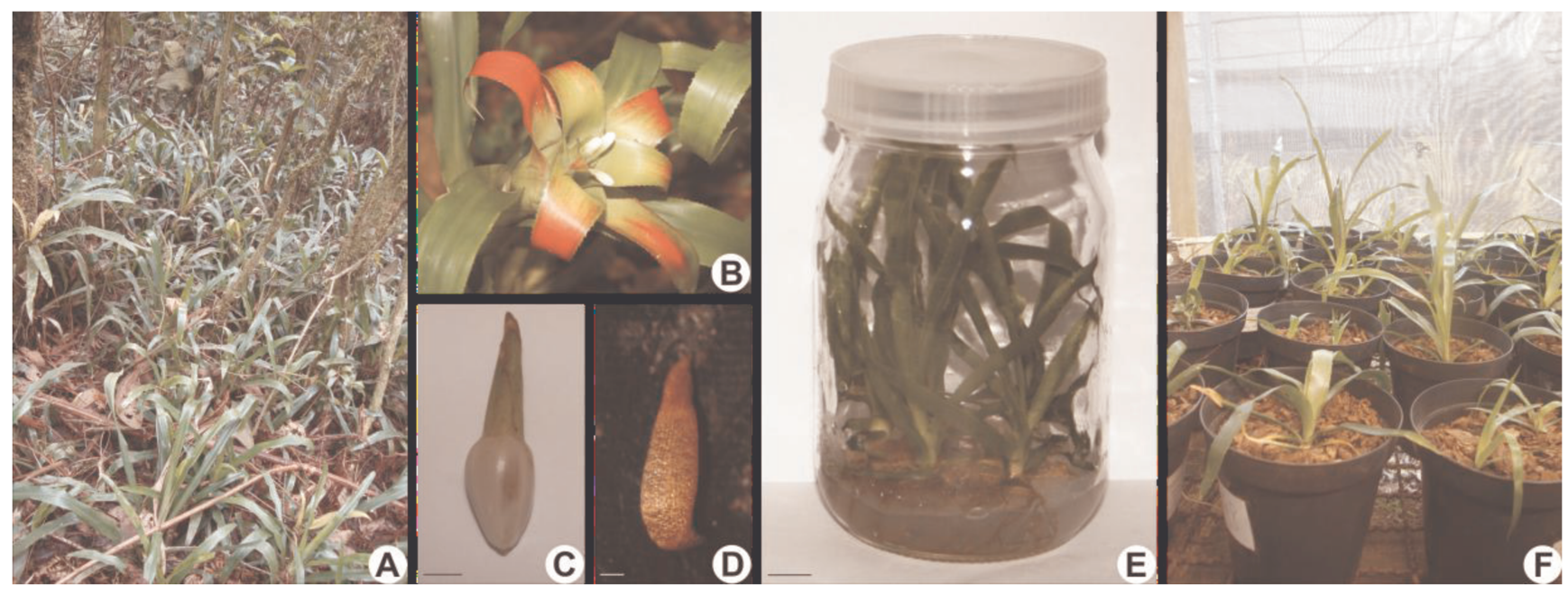

\section{Demo Version, htttp://www.verydloc.com andl htttp://www.verypdif.com}


agosto de 2008, sendo que apenas para a análise da duração das flores as observações foram diárias. $\mathrm{O}$ início das observações ocorreu com o aparecimento das primeiras brácteas florais (Figura 1B). Foram avaliados o comprimento da planta, número de brotos e tamanho dos brotos. Em seguida contou-se o número de botões florais, registrando o tempo entre o início da floração e da frutificação, além do número de frutos (Figura 1C) por planta. Foram selecionados aleatoriamente três frutos para a contagem das sementes (Figura 1D).

Adicionalmente, verificou-se o tempo necessário para que um broto isolado atingisse a floração, visto que a propagação vegetativa por meio da emissão de brotos laterais por estolões é uma das principais formas de propagação desta espécie. Para isso, foram destacados brotos da planta mãe e colocados em vasos contendo casca de Pinus como substrato. As plantas foram irrigadas semanalmente e receberam nutrientes na concentração de 1 g.L $\mathrm{L}^{-1}$ de adubo comercial Peters ${ }^{\circledR}$ 20:20:20 (N:P:K) a cada 15 dias.

As sementes utilizadas para o estabelecimento do cultivo in vitro foram provenientes de diferentes exemplares de populações da Estação Biológica do Alto da Serra de Paranapiacaba, incluindo aquelas selecionadas para os estudos fenológicos.

\section{Cultivo in vitro}

\section{Desinfestação das sementes}

O cultivo in vitro foi iniciado a partir da desinfestação de sementes que foram imersas, primeiramente em etanol $70 \%$ por $3 \mathrm{~min}$. Após enxágue, testaram-se soluções de hipoclorito de sódio a 1 e $2 \%$ de cloro ativo por 30, 60 e $90 \mathrm{~min}$, visando estabelecer a menor taxa de contaminação com menor custo. Para cada tratamento, utilizaram-se 100 sementes distribuídas em quatro placas de Petri (25 sementes/placa) com $10 \mathrm{~mL}$ de meio de cultura contendo $2 \%$ de sacarose e gelificado com 6 g.L $\mathrm{L}^{-1}$ de agar. O delineamento experimental foi inteiramente casualizado, sendo que nos experimentos de germinação cada placa de Petri foi considerada uma unidade experimental. As placas foram mantidas sob fotoperíodo de $12 \mathrm{~h}$ com radiação fotossinteticamente ativa de 30 $\mu \mathrm{mol} . \mathrm{m}^{-2} \mathrm{~s}^{-1}$ (MOLLO et al., 2011) e temperatura média de $26 \pm 2^{\circ} \mathrm{C}$. A eficiência da desinfestação foi avaliada conforme a porcentagem de contaminação das sementes em cada placa, durante o período de 30 dias.

\section{Germinação in vitro em diferentes meios nutritivos}

Foram testados os seguintes meios nutritivos constituídos por: $1 \%$ de sacarose (S1); $2 \%$ de sacarose (S2); macronutrientes da formulação de Knudson (1946) (K) acrescidos de 3\% de sacarose e 0,01\% de myo-inositol; formulação de Murashige e Skoog (1962) (MS) acrescidos de 3\% de sacarose e 0,01\% de myo-inositol; e outro tratamento contendo a metade da concentração dos sais de macronutrientes do MS acrescidos de $3 \%$ de sacarose e $0,01 \%$ de myo-inositol (MS/2). Em todos os tratamentos, o agente gelificante foi o agar na concentração de 6 g.L $\mathrm{L}^{-1}$. O pH dos meios foi ajustado para 5,8. Foram depositadas 25 sementes em cada uma das quatro placas de Petri (100 sementes por tratamento) para cada um dos cinco meios nutritivos. $\mathrm{O}$ delineamento experimental foi inteiramente casualizado, sendo que nos experimentos de germinação cada placa de Petri foi considerada uma unidade experimental. As placas foram mantidas sob fotoperíodo de $12 \mathrm{~h}$. com radiação fotossinteticamente ativa de $30 \mu \mathrm{mol} \cdot \mathrm{m}^{-2} \cdot \mathrm{s}^{-1}$ e a temperatura média de $26 \pm 2^{\circ} \mathrm{C}$ até a ocorrência da germinação das sementes, considerada a partir da emissão da radícula, sendo estas as condições frequentemente relatadas para o cultivo in vitro de bromélias (MERCIER; KERBAUY, 1995).

\section{Germinação in vitro em diferentes temperaturas}

Após a identificação do meio nutritivo mais adequado no experimento anterior, foram testadas três condições térmicas visando avaliar a influência sobre a germinação das sementes: $15^{\circ} \mathrm{C}$ (constante-claro/ escuro); $26^{\circ} \mathrm{C}$ (constante-claro/escuro); e temperaturas alternadas entre o período com luz $\left(30^{\circ} \mathrm{C}\right)$ e o escuro $\left(15^{\circ} \mathrm{C}\right)$. Foram utilizadas 100 sementes distribuídas em quatro placas de Petri (25 sementes/placa), contendo o meio nutritivo selecionado no experimento anterior, para cada um dos tratamentos térmicos. O delineamento experimental foi inteiramente casualizado, sendo que 
nos experimentos de germinação cada placa de Petri foi considerada uma unidade experimental. Em todos os tratamentos testados as sementes foram mantidas sob fotoperíodo de $12 \mathrm{~h}$ com radiação fotossinteticamente ativa de $30 \mu \mathrm{mol} \cdot \mathrm{m}^{-2} \cdot \mathrm{s}^{-1}$. A porcentagem de germinação foi avaliada aos 30 e 45 dias.

\section{Crescimento in vitro em diferentes meios nutritivos}

Após a seleção da faixa da temperatura ideal para a germinação das sementes (experimento anterior), foi avaliado o crescimento das plantas mantidas em cultivo nos seguintes meios nutritivos: $\mathrm{K}, \mathrm{MS}$ e $\mathrm{MS} / 2$, sendo que em todos os tratamentos os micronutrientes foram adicionados conforme descrito para MS e acrescidos de 6 g.L.-1 de agar. O pH dos meios foi ajustado para 5,8. O delineamento experimental empregado foi o inteiramente casualizado, com os tratamentos arranjados em um esquema fatorial $3 \times 5$, com 50 plantas por tratamento, distribuídas em cinco repetições (em frascos de $250 \mathrm{~mL}$, com $40 \mathrm{~mL}$ de meio) contendo 10 plantas por repetição. Os frascos foram mantidos em sala de cultura com fotoperíodo de $12 \mathrm{~h}$ com radiação fotossinteticamente ativa de $30 \mu \mathrm{mol} \cdot \mathrm{m}^{-2} . \mathrm{s}^{-1}$ na temperatura selecionada de acordo com os resultados observados no item anterior. Aos três meses foi feito um subcultivo para meios novos. Após seis meses da implantação do experimento, foram determinados os comprimentos e a massa seca da parte aérea, bem como os teores de pigmentos fotossintéticos (clorofilas $a, b$ ) e carotenoides.

\section{Crescimento in vitro em diferentes temperaturas}

Neste estudo, foram utilizadas 200 plântulas com um mês de idade obtidas a partir da germinação in vitro nas condições estabelecidas de acordo com os resultados anteriores. Essas plântulas foram transferidas para frascos de $250 \mathrm{~mL}$ contendo $40 \mathrm{~mL}$ de meio selecionado a partir dos resultados do experimento anterior. Os frascos foram mantidos em diferentes temperaturas que podem ocorrer no ambiente natural desta espécie: $15^{\circ} \mathrm{C}$ (constante- claro/escuro); $26^{\circ} \mathrm{C}$ (constante- claro/ escuro); $30^{\circ} \mathrm{C}$ (constante- claro/escuro); e temperaturas alternadas entre o período com luz $\left(30^{\circ} \mathrm{C}\right)$ e o escuro $\left(15^{\circ} \mathrm{C}\right)$. $\mathrm{O}$ delineamento experimental empregado foi o inteiramente casualizado, com os tratamentos arranjados em um esquema fatorial $4 \times 5$, com 50 plantas por tratamento, distribuídas em cinco repetições (em frascos de $250 \mathrm{~mL}$, com $40 \mathrm{~mL}$ de meio) contendo 10 plantas por repetição. Todos os tratamentos foram mantidos sob fotoperíodo de $12 \mathrm{~h}$ com radiação fotossinteticamente ativa de $30 \mu \mathrm{mol} \cdot \mathrm{m}^{-2} \cdot \mathrm{s}^{-1}$ em câmaras de germinação/ crescimento ajustadas com as temperaturas analisadas. Após seis meses, foram determinados: o comprimento da parte aérea e o teor de pigmentos fotossintéticos (clorofilas $a$ e $b$ ).

\section{Teores de pigmentos fotossintéticos}

Os teores de clorofila $a$ e $b$ e carotenoides foram determinados segundo Lichtenthaler (1987). As análises foram realizadas em três amostras de $0,5 \mathrm{~g}$ de MF foliar, provenientes da coleta de 20 plantas, as quais foram maceradas com $3 \mathrm{~mL}$ de acetona pura refrigerada a $10^{\circ} \mathrm{C}$. As amostras foram filtradas em funil previamente forrado com papel de filtro umedecido com acetona refrigerada. Após a filtragem, o papel de filtro foi lavado exaustivamente com acetona até a remoção de todos os pigmentos. As amostras foram coletadas em balões volumétricos de $25 \mathrm{~mL}$ e avaliadas em espectrofotômetro ( $A=$ absorbância). As concentrações da clorofila $a(C a)$, da clorofila $b(\mathrm{Cb})$ e dos carotenoides $(C)$ foram obtidas pelas equações apresentadas a seguir:

$$
\begin{aligned}
& C a=11,24 A_{661,6}-2,04 A_{644,8} \\
& C b=20,13 A_{644,8}-4,19 A_{661,6} \\
& C=\left(1000 A_{470} \square 1,90 C a \square 63,14 C b\right) / 214
\end{aligned}
$$

Os conteúdos de clorofilas dos tecidos foram expressos em $\mu \mathrm{g}$ de pigmento por grama de MF foliar.

\section{Aclimatização das plantas após cultivo in vitro}

Após selecionado o meio de cultivo que possibilitou o melhor crescimento das plantas produzidas in vitro, um lote de 50 plantas micropropagadas por seis meses nesse tratamento, foi transferido para condições de crescimento ex vitro em casa de vegetação, conforme protocolo modificado de Tamaki et al. (2011). Foram 
utilizadas bandejas de isopor, do tipo sementeira, contendo casca de Pinus triturada e compostada como substrato. As plantas foram adubadas quinzenalmente com 1 g. L $^{-1}$ de adubo comercial Peters ${ }^{\circledR}$ 20:20:20 (N:P:K) e foi avaliada a porcentagem de sobrevivência das plantas após três meses de cultivo.

\section{Análise estatística}

Os dados em porcentagem de germinação foram previamente transformados para $\sqrt{ }$ arc sen. Os valores dos parâmetros biométricos foram submetidos à análise de variância (ANOVA), em seguida as médias foram comparadas pelo teste Tukey em nível de 5\% de probabilidade. Os resultados de todos os experimentos e estudos fenológicos foram apresentados com as médias seguidas de seus respectivos desvios padrões

\section{Resultados}

\section{Identificação do período de frutificação}

Os dados das observações fenológicas entre setembro de 2007 a agosto de 2008 estão indicados na Tabela 1.

As primeiras brácteas florais apareceram em setembro, antecedendo o início do aparecimento das primeiras flores (novembro), seguido pelo surgimento das brotações, indicando início de propagação vegetativa em dezembro, que se estendeu até julho de 2008. Após o surgimento dos brotos, foi constatado o início da senescência da planta mãe.

Entre as 21 plantas analisadas, somente três floresceram $(14,3 \%)$ e destas, apenas uma formou frutos com sementes $(5,0 \%)$. A altura das plantas foi de $20,3 \pm$ $3,2 \mathrm{~cm}$ para as que floresceram e, de modo interessante, os brotos eram mais altos, atingindo $28,9 \pm 1,8 \mathrm{~cm}$ em média, indicando o investimento reprodução vegetativa. Do total de plantas, $38 \%$ entraram em senescência e secaram (cerca de oito plantas) antes de atingirem a fase de floração, porém, apesar de não terem se reproduzido sexuadamente, propagaram-se vegetativamente, emitindo $3 \pm 1$ brotos por planta.

Observou-se a produção de 29,7 $\pm 3,5$ flores por planta. A duração de cada flor foi de aproximadamente sete dias e o período de floração estendeu-se até dezembro. A frutificação ocorreu de janeiro a junho, sendo observados cerca de 22,0 $\pm 2,0$ frutos por planta, destes apenas 4,5 $\pm 0,7$ produziram sementes. De junho a agosto de 2008 foram produzidas 193,0 $\pm 114,1$ sementes por fruto. Estes frutos apresentavam aspecto translúcido que permitia visualizar a cor castanho escuro das sementes consideradas maduras no seu interior, de acordo com resultados de experimentos preliminares.

Dentre as 21 plantas analisadas, além das três que floresceram, sete continuaram em estado vegetativo e 11 emitiram brotações $(52,4 \%)$, resultando em um total de 34 brotos (1,62 brotos por planta na população), dos quais 20,6\% floresceram após 12 meses (em novembro de 2008). Dos 34 brotos gerados, utilizou-se 20, que foram destacados da planta mãe e transferidos para vasos,

TABELA 1: Aspectos fenológicos de plantas de Nidularium minutum Mez da Estação Biológica do Alto da Serra de Paranapiacaba-SP-Brasil, no período de setembro de 2007 a agosto de 2008. (X=indica o período de ocorrência do evento).

\begin{tabular}{|c|c|c|c|c|c|c|c|c|c|c|c|c|}
\hline \multirow{2}{*}{ Evento } & \multicolumn{4}{|c|}{2007} & \multicolumn{8}{|c|}{2008} \\
\hline & $\mathbf{S}$ & $\mathbf{O}$ & $\mathbf{N}$ & D & $\mathbf{J}$ & $\mathbf{F}$ & $\mathbf{M}$ & $\mathbf{A}$ & M & $\mathbf{J}$ & $\mathbf{J}$ & $\mathbf{A}$ \\
\hline Brácteas florais & $\mathrm{X}$ & $\mathrm{X}$ & $\mathrm{X}$ & $\mathrm{X}$ & & & & & & & & \\
\hline Floração & & & $X$ & $X$ & & & & & & & & \\
\hline Frutificação & & & & & $\mathrm{X}$ & $\mathrm{X}$ & $\mathrm{X}$ & $\mathrm{X}$ & $\mathrm{X}$ & $\mathrm{X}$ & & \\
\hline Sementes maduras & & & & & & & & & & $\mathrm{X}$ & $\mathrm{X}$ & $\mathrm{X}$ \\
\hline Emissão de brotos & & & & $\mathrm{X}$ & $\mathrm{X}$ & $\mathrm{X}$ & $\mathrm{X}$ & $\mathrm{X}$ & $\mathrm{X}$ & $\mathrm{X}$ & $\mathrm{X}$ & \\
\hline
\end{tabular}


sendo realizado nestes o acompanhamento fenológico. Estes brotos enraizaram e sobreviveram em condições de casa de vegetação. Devido ao fato de apenas $5 \%$ das plantas apresentarem frutos com sementes optou-se por utilizar, para viabilizar o estabelecimento do protocolo de cultivo in vitro, sementes provenientes de diferentes exemplares de outras populações da Estação Biológica do Alto da Serra de Paranapiacaba, incluindo aquelas selecionadas para os estudos fenológicos.

\section{Cultivo in vitro}

\section{Desinfestação de sementes e germinação em diferentes meios}

A porcentagem de contaminação por fungos e bactérias das sementes submetidas à desinfestação por quaisquer um dos tratamentos testados foi de $16 \%$ e nenhum deles induziu a morte das sementes. Assim, optou-se pelo tratamento com $1 \%$ de hipoclorito de sódio por 30 min. Não houve diferença significativa entre a porcentagem de germinação das sementes depositadas nos meios MS, MS/2, K, S1 e S2 (Tabela 2), embora em MS/2 tenha sido observado um maior valor absoluto de média.

TABELA 2: Germinação (\%) de sementes de Nidularium minutum Mez em diferentes meios nutritivos (MS = formulação de Murashige e Skoog; $\mathrm{MS} / 2=\mathrm{MS}$ contendo macronutrientes reduzidos à metade; $\mathrm{K}=$ formulação de Knudson; $\mathrm{S} 1=$ só agar e $1 \%$ sacarose; $\mathrm{S} 2=$ só agar e $2 \%$ sacarose). Médias, e seus respectivos desvios padrões $(n=4)$, acompanhadas por letras distintas indicam diferenças estatísticas em 5\% de probabilidade pelo teste Tukey.

\begin{tabular}{lc}
\hline \multicolumn{1}{c}{ Meios Nutritivos } & Germinação * \\
\hline MS & $42,65 \pm 5,63 \mathrm{a}$ \\
MS/2 & $43,98 \pm 5,48 \mathrm{a}$ \\
K & $29,50 \pm 7,56 \mathrm{a}$ \\
S1 & $33,10 \pm 16,40 \mathrm{a}$ \\
S2 & $40,24 \pm 2,66 \mathrm{a}$ \\
\hline
\end{tabular}

* Os dados em porcentagem de germinação foram previamente transformados para Varc sen.

\section{Germinação in vitro em diferentes temperaturas}

As diferenças entre os tratamentos ocorreram apenas em relação ao tempo de início da germinação das sementes e não em relação à porcentagem final, que atingiu, após 45 dias, cerca de $60 \%$ para todos os tratamentos. Os resultados mostraram que, em 30 dias, a maior porcentagem de germinação ocorreu a $26^{\circ} \mathrm{C} \mathrm{em}$ relação às demais temperaturas (Tabela 3 ).

TABELA 3: Germinação (\%) de sementes de Nidularium minutum Mez após 30 e 45 dias em diferentes temperaturas: $15^{\circ} \mathrm{C}$ (constante-claro/escuro), $26^{\circ} \mathrm{C}$ (constante-claro/escuro) e temperaturas alternadas entre o período com luz $\left(30^{\circ} \mathrm{C}\right)$ e o escuro $\left(15^{\circ} \mathrm{C}\right)$. Médias, e seus respectivos desvios padrões $(n=4)$, acompanhadas por letras minúsculas distintas indicam diferenças estatísticas em $5 \%$ de probabilidade pelo teste Tukey.

\begin{tabular}{lccc}
\hline & \multicolumn{3}{c}{ Temperaturas } \\
\cline { 2 - 4 } & $\mathbf{1 5}^{\mathbf{}} \mathbf{C}$ & $\mathbf{2 6}^{\circ} \mathbf{C}$ & $\begin{array}{c}\mathbf{3 0}^{\circ} \mathbf{C} \\
\text { claro } / \mathbf{1 5}^{\circ} \mathbf{C} \\
\text { escuro }\end{array}$ \\
\hline $\begin{array}{l}\text { Germinação } \\
\text { aos 30 dias* }\end{array}$ & $33,18 \pm 6,09$ b & $48,71 \pm 8,69$ a & $36,11 \pm 6,01$ b \\
$\begin{array}{l}\text { Germinação } \\
\text { aos 45 dias* }\end{array}$ & $58,98 \pm 4,03$ a & $61,67 \pm 3,37$ a & $60,43 \pm 5,11$ a \\
\hline
\end{tabular}

* Os dados em porcentagem de germinação foram previamente transformados para Varc sen.

A germinação levou em média cinco dias para iniciar nas temperaturas de $26^{\circ} \mathrm{C}$ e na temperatura alternada entre o período com luz $\left(30^{\circ} \mathrm{C}\right)$ e o escuro $\left(15^{\circ} \mathrm{C}\right)$. Naquelas mantidas a $15^{\circ} \mathrm{C}$ o início da germinação ocorreu em cerca de 20 dias.

\section{Crescimento in vitro e aclimatização}

O melhor meio para o crescimento das plantas foi o MS/2 (Figura 1E), apresentando médias superiores tanto para a quantidade de massa seca quanto para os teores de pigmentos fotossintéticos (Tabela 4). 
TABELA 4: Crescimento e teores de pigmentos fotossintéticos (clorofila $a$ e $b$ e carotenoides) em plantas de Nidularium minutum Mez cultivadas in vitro em diferentes meios nutritivos. (MS = formulação de Murashige e Skoog; $\mathrm{MS} / 2$ = MS contendo macronutrientes reduzidos à metade da concentração; $\mathrm{K}$ = formulação de Knudson). Médias, e seus respectivos desvios padrões $(n=50)$, acompanhadas por letras minúsculas distintas indicam diferenças estatísticas em 5\% de probabilidade pelo teste Tukey dentro de um mesmo parâmetro analisado.

\begin{tabular}{cccc}
\hline & \multicolumn{3}{c}{ Tratamentos } \\
& MS & MS $/ \mathbf{2}$ & K \\
\hline Comprimento da parte aérea $(\mathrm{cm})$ & $2,42 \pm 0,59 \mathrm{a}$ & $3,28 \pm 0,97 \mathrm{a}$ & $2,21 \pm 0,66 \mathrm{a}$ \\
Massa seca da parte aérea por planta $(\mathrm{g})$ & $0,020 \pm 0,001 \mathrm{~b}$ & $0,040 \pm 0,013 \mathrm{a}$ & $0,030 \pm 0,004 \mathrm{ab}$ \\
Clorofila $a\left(\mathrm{mg} \mathrm{gMF}^{-1}\right)$ & $1,16 \pm 0,17 \mathrm{a}$ & $1,00 \pm 0,06 \mathrm{a}$ & $0,73 \pm 0,03 \mathrm{~b}$ \\
Clorofila $b\left(\mathrm{mg}^{-1} \mathrm{gMF}^{-1}\right)$ & $0,41 \pm 0,05 \mathrm{a}$ & $0,37 \pm 0,02 \mathrm{a}$ & $0,32 \pm 0,01 \mathrm{~b}$ \\
Carotenoides $\left(\mathrm{mg}_{\mathrm{gMF}}{ }^{-1}\right)$ & $0,29 \pm 0,04 \mathrm{a}$ & $0,24 \pm 0,02 \mathrm{a}$ & $0,20 \pm 0,09 \mathrm{~b}$ \\
\hline
\end{tabular}

Com relação à temperatura para crescimento das plantas, observou-se que os valores dos comprimentos da parte aérea e as quantidades de clorofilas $a$ e $b$ das plantas mantidas a $26^{\circ} \mathrm{Ce} 30^{\circ} \mathrm{C}$ (constante claro/escuro) não apresentaram diferenças significativas entre si apresentando médias maiores que aquelas mantidas a $15^{\circ} \mathrm{C}$ e em temperaturas alternadas entre o período com luz $\left(30^{\circ} \mathrm{C}\right)$ e escuro $\left(15^{\circ} \mathrm{C}\right)$ (Tabela 5). Observouse também que $40 \%$ das plantas mantidas a $30^{\circ} \mathrm{C}$ apresentaram de três a quatro brotos ao final de seis meses de cultivo, não sendo identificadas brotações nos demais tratamentos.

As plantas produzidas in vitro foram aclimatizadas em casa de vegetação tendo sido constatado, após três meses de cultivo ex vitro, $100 \%$ de sobrevivência das plantas (Figura 1F) e não foram observadas brotações nessa fase.

\section{Discussão}

O acompanhamento das etapas fenológicas de $N$. minutum verificado neste trabalho possibilitou conhecer o intervalo de tempo entre a floração e a consequente produção de sementes maduras durante o período de setembro de 2007 a agosto de 2008, sendo possível planejar as viagens para coleta. A floração de $N$. minutum observada neste trabalho teve início em novembro de 2007, no entanto, Wanderley e Martins (2007) relataram que essa espécie pode florescer entre janeiro e fevereiro. Essas diferenças indicam a importância dos estudos na determinação da época de produção de sementes, tal como relatado por Negrelle e Muraro (2006) para a bromélia Vriesea incurvata Gaudich. Esses mesmos autores verificaram que foram necessários cerca de seis meses para obtenção de sementes maduras após a floração, a semelhança do observado neste trabalho para N. minutum.

TABELA 5: Comprimento da parte aérea e quantidade de pigmentos fotossintéticos (clorofila $a$ e $b$ ) de Nidularium minutum Mez em diferentes temperaturas de crescimento após seis meses de crescimento em meio MS/2.

\begin{tabular}{|c|c|c|c|c|}
\hline & \multicolumn{4}{|c|}{ Temperaturas } \\
\hline & $15^{\circ} \mathrm{C}$ & $26^{\circ} \mathrm{C}$ & $30^{\circ} \mathrm{C}$ & $30^{\circ} \mathrm{C} / 15^{\circ} \mathrm{C}$ \\
\hline Comprimento da parte aérea $(\mathrm{cm})$ & $3,46 \pm 0,52 \mathrm{~b}$ & $12,46 \pm 1,28 \mathrm{a}$ & $10,32 \pm 1,57 \mathrm{a}$ & $4,00 \pm 0,90 \mathrm{~b}$ \\
\hline Clorofila $\boldsymbol{a}\left(\mathrm{mg} \mathrm{gMF}^{-1}\right)$ & $0,41 \pm 0,11 \mathrm{~b}$ & $0,78 \pm 0,14 \mathrm{a}$ & $0,62 \pm 0,33$ a & $0,31 \pm 0,02 \mathrm{~b}$ \\
\hline Clorofila $\boldsymbol{b}\left(\left(\mathrm{mg} \cdot \mathrm{gMF}^{-1}\right)\right.$ & $0,22 \pm 0,03 \mathrm{~b}$ & $0,31 \pm 0,03 \mathrm{a}$ & $0,30 \pm 0,10 \mathrm{a}$ & $0,20 \pm 0,01 \mathrm{~b}$ \\
\hline
\end{tabular}


Nas populações estudadas a produção de sementes foi baixa, visto que das 21 plantas observadas apenas $5 \%$ apresentaram frutos com sementes. No caso de $N$. minutum, é importante salientar que a reprodução assexuada por meio de estolões é duradouro (oito meses), o que assegura, de modo complementar, a sua propagação na natureza, visto que poucas plantas produzem sementes anualmente.

O estabelecimento do cultivo in vitro de $N$. minutum, utilizando sementes iniciou-se pela desinfestação utilizando-se $1 \%$ de hipoclorito de sódio por $30 \mathrm{~min}$. $\mathrm{O}$ presente protocolo combina menor concentração de hipoclorito de sódio com menor tempo de imersão das sementes. Outros protocolos utilizam concentrações mais elevadas de hipoclorito de sódio em até $2 \%$ ou exposição por até $1 \mathrm{~h}$ nessa solução. Esses procedimentos podem estar relacionados à presença de apêndices plumosos como em Vriesea fosteriana L.B. Sm e $V$. hieroglyphica (MERCIER; KERBAUY, 1995) e Vriesea gigantea Mart. ex Schult. f. (ENDRES et al., 2002) ou alados como em Dyckia maritima Baker (SILVA et al., 2008), pois esses apêndices nas sementes podem reter microorganismos que contaminariam o meio de cultura, o que não ocorre para $N$. minutum.

Os resultados do experimento de germinação em diferentes meios nutritivos mostraram que não há necessidade de utilização de sais minerais nesse processo, pois apenas com $1 \%$ de sacarose obtiveram-se porcentagens de germinação estatisticamente iguais aos demais tratamentos. Observou-se, portanto, que a maior concentração de sacarose e a presença de sais nos demais tratamentos não prejudicaram o processo da emissão da radícula, talvez por não terem indisponibilizado a água para o processo de embebição das sementes. Resultados semelhantes foram encontrados por Pereira et al. (2011), que não observaram diferenças nas porcentagens de germinação in vitro de sementes da bromélia Pitcairnia flammea Lindl. em diferentes meios de cultivo contendo ou não sais minerais.

Os resultados demonstraram que a temperatura de $26^{\circ} \mathrm{C}$ induziu a germinação de sementes de $N$. minutum em menor tempo de cultivo que as demais temperaturas utilizadas, à semelhança de outros trabalhos com as bromélias Bromelia antiacantha Bertol. (MERCIER;
YOSHIDA, 1998), Neoglaziovia variegata (Arruda) Mez (SILVEIRA et al., 2009) e $V$. gigantea (ENDRES et al., 2002). A porcentagem de germinação a $15^{\circ} \mathrm{C}$ foi semelhante àquelas observadas para as demais temperaturas testadas, apenas tendo sido necessário um maior tempo de cultivo. Resultados semelhantes com o uso de baixas temperaturas na germinação foram observados para outras duas bromélias, A. imperialis (MOLLO et al., 2011) e D. encholirioides (Gaudichaud) Mez (POMPELLI et al., 2006).

Nas temperaturas de $26^{\circ} \mathrm{C}$ e $30^{\circ} \mathrm{C}$, foi observado o maior crescimento de $N$. minutum, entretanto, a utilização da temperatura mais elevada $\left(30^{\circ} \mathrm{C}\right)$ induziu a produção de brotos em $40 \%$ das plantas cultivadas in vitro. Hua (2009) relata que a temperatura de $30^{\circ} \mathrm{C}$ pode induzir a transcrição de genes relacionados ao metabolismo de auxinas provocando alterações na arquitetura da planta. Contudo, a produção de brotos também pode ser utilizada como técnica de propagação devido à possibilidade de isolamento destes e transferência para novo meio de cultura. Essa pode ser uma abordagem para estudos futuros visando à produção de clones dessa espécie, como realizado para outras bromélias (SANTOS et al., 2010).

Quanto à composição do meio nutritivo, observouse que o crescimento das plantas de $N$. minutum ocorreu mais satisfatoriamente no tratamento $\mathrm{MS} / 2 \mathrm{em}$ comparação aos demais utilizados no presente trabalho. Diluições do meio MS em sua formulação original têm sido utilizadas na micropropagação de bromélias como relatado para $V$. hieroglyphica (MERCIER; KERBAUY, 1994), Ananas comosus (L.) Merril cultivar Smooth Cayene (TAMAKI et al., 2007), V. friburgensis Mez e $V$. unilateralis (Baker) Mez (ARANDA-PEREZ et al., 2009). Estudos recentes com N. minutum mostraram que essa espécie sobrevive por pelo menos 180 dias sob deficiência de nitrogênio, fósforo e potássio, indicando capacidade de tolerar ambientes, nutricionalmente, mais diluídos (ANDRADE; TAMAKI, 2012).

As plantas cultivadas in vitro em meio $\mathrm{MS} / 2$ apresentaram, aos seis meses, um sistema radicular bem desenvolvido e em razão de seu entrelaçamento a realização de avaliações biométricas não foi possível, contudo, a presença de raízes desenvolvidas, 
possivelmente, está relacionada ao sucesso da aclimatização de $N$. minutum observada nesse trabalho, a semelhança do ocorrido na bromélia $A$. imperialis (AOYAMA et al., 2012).

Os dados de comprimento e massa seca da parte aérea mostram que $\mathrm{MS} / 2$ e $\mathrm{K}$ induziram crescimento satisfatório de $N$. minutum, contudo os maiores valores de pigmentos fotossintéticos sugerem que o MS/2 possa ser o mais adequado para o cultivo in vitro dessa bromélia, visto que esses compostos podem ser indicadores de eficiente nutrição nitrogenada (TAMAKI et al., 2007; WIEDENFELD et al., 2009). Em outros trabalhos com as bromélias A. imperialis (AOYAMA et al., 2012), $V$. inflata (PEDROSO et al., 2010) e Dyckia maritima Baker (SILVA et al., 2008), também foi selecionado o meio $\mathrm{MS} / 2$ para o cultivo in vitro.

No presente trabalho, observou-se que $100 \%$ das plantas de $N$. minutum cultivadas in vitro por seis meses em meio $\mathrm{MS} / 2$ e a $26^{\circ} \mathrm{C}$ sobreviveram à fase de aclimatização, sendo possível a produção de mudas em larga escala.

Conclui-se que o período de julho a agosto é o mais indicado para a coleta das sementes visando a propagação de N. minutum. A produção in vitro a partir de sementes de $N$. minutum é eficientemente realizada quando estas são desinfestadas com $1 \%$ de hipoclorito de sódio por 30 min e germinadas a $26^{\circ} \mathrm{C}$. O maior desenvolvimento das plantas ocorre nessa mesma temperatura em meio MS/2. É possível aclimatizá-las ex vitro com sucesso. Devido à baixa produção de sementes in situ, o cultivo in vitro destaca-se como uma importante ferramenta para o uso e a conservação desta espécie.

\section{Referências}

ANDRADE, S.; TAMAKI, V. Influence of NPK on the growth of bromeliad Nidularium minutum Mez. cultivated in vitro. Communications in Plant Sciences, Lages, v. 2, n. 3-4, p. $137-$ 139, 2012.

AOYAMA, E. M.; VERSIEUX, L. M.; NIEVOLA, C. C.; MAZZONI-VIVEIROS, S. C. Avaliação da eficiência da propagação de Alcantarea imperialis (Bromeliaceae) cultivada in vitro e ex vitro. Rodriguésia, Rio de Janeiro, v. 63, n. 2, p. 321-331, 2012.

ARANDA-PEREZ, A. N.; PERES, L. E. P.; HIGASHI, E. N.; MARTINELLI, A. P. Adjustment of mineral elements in the culture medium for the micropropagation of three Vriesea bromeliads from the brazilian Atlantic Forest: the importance of calcium. HortScience, Alexandria, n. 44, p. 106-112, 2009.

ARRABAL, R.; AMANCIO, F.; CARNEIRO, L. J.; NEVES, L. J.; MANSUR, E. Micropropagation of endangered endemic brazilian bromeliad Cryptanths sinuosus (L. B. Smith) for in vitro preservation. Biodiversity and Conservation, New York, v. 11, p. 1081-1089, 2002.

ENDRES, L.; SOUZA, B. M.; MERCIER, H. In vitro nitrogen nutrition and hormonal pattern in bromeliads. In Vitro Cellular Development Biology-Plant, Dordrecht, v. 38, p. 481-486, 2002.

ENGELMANN, F. Use of biotechnologies for the conservation of plant biodiversity. In Vitro Cellular \& Developmental BiologyPlant, Dordrecht, v. 47, p. 5-16, 2010.

FRESCHI, L.; TAKAHASHI, C. A.; CAMBUI, C. A.; SEMPREBOM, T. R.; CRUZ, A. B.; MIOTO, P. T.; DE MELO VERSIEUX; L.; CALVENTE, A.; LATANSIO-AIDAR, S. R.; AIDAR, M. P. M; MERCIER, H. Specific leaf areas of the tank bromeliad Guzmania monostachia perform distinct functions in response to water shortage. Journal of Plant Physiology, Tübingen, v. 167, p. 526-533, 2010.

GOODE, L. K.; ALLEN, M. F. Seed germination conditions and implications for establishment of an epiphyte, Aechmea bracteata (Bromeliaceae). Plant Ecology, Dordrecht, v. 204, p. 179 $\square 88$, 2009.

GUTJAHR, M.R.; TAVARES, R. Clima. In.: LOPES, M. I. M. S.; KIRIZAWA, M.; MELO, M. M. R. F. (Org.). Patrimônio da Reserva Biológica do Alto da Serra de Paranapiacaba: a antiga Estação Biológica do Alto da Serra. São Paulo: Instituto de Botânica, 2009. p. 39-51.

HUA, J. From freezing to scorching, transcriptional responses to temperature variations in plants. Current Opinion in Plant Biology, Saint Louis, v. 12, p. 568-573, 2009.

KIMBERLY, A. P.; AFFOLTER, J. M.; WETZSTEIN, H. Y. Enhanced seed germination and seedling growth of Tillandsia eizii in vitro. HortScience, Alexandria, v. 38, p. 101-104, 2003.

KNUDSON, L. A new nutrient solution for germination of orchid seed. American Orchid Society Bulletin, Coral Gables, v. 15, p. 214-217, 1946.

LICHTENTHALER, H. K. Chlorophylls and carotenoids: pigments of photosynthetic biomembranes. In: PACKER L.; DOUCE R. (Ed.). Methods in enzimology. London: Academic Press, 1987. p. 350-382.

LUTHER, H. E. An alphabetical list of bromeliad binomials. Florida: Bromeliad Society Internacional, 2010. 45 p.

MAMEDE, M. C. H.; SOUZA, V. C.; PRADO, J.; BARROS, F.; WANDERLEY, M. G. L.; RANDO, J. G. Livro vermelho das espécies vegetais ameaçadas de extinção no Estado de São Paulo. São Paulo: Instituto de Botânica, 2007. 165 p.

MYERS, N.; MITTERMEIER, R. A; FONSECA, G. A. B.; KENT, J. Biodiversity hotspots for conservation priorities. Nature, London, v. 403, p. 853-858, 2000.

MERCIER, H.; KERBAUY, G. B. In vitro culture of Vriesea hieroglyphica, an endangered bromeliad from the brazilian Atlantic Forest. Journal of the Bromeliad Society, Florida, v. 44, p. 120 124,1994 
MERCIER, H.; KERBAUY, G. B. The importance of tissue culture technique for conservation of endangered brazilian bromeliads from Atlantic Rain Forest canopy. Selbyana, Sarasota, v. 16, p. 147-149, 1995.

MERCIER, H.; YOSHIDA, M. K. Bromelain activity in the leaf tissue of Bromelia antiacantha. Journal of the Bromeliad Society, Florida, v. 48, p. 6-10, 1998.

MOLLO, L.; MARTINS, M. C. M.; OLIVEIRA, V. F.; NIEVOLA, C. C.; FIGUEIREDO-RIBEIRO, R. C. Effects of low temperature on growth and non-structural carbohydrates of the imperial bromeliad Alcantarea imperialis cultured in vitro. Plant Cell, Tissue and Organ Culture, Dordrecht, v. 107, p. 141-149, 2011.

MURASHIGE, T.; SKOOG, F. A revised medium for rapid growth and bioassays with tobacco tissue cultures. Physiologia Plantarum, Lund, v. 15, p. 473-497, 1962.

NEGRELLE, R. R. B.; MURARO, D. Aspectos fenológicos e reprodutivos de Vriesea incurvata Gaudich (Bromeliaceae). Acta Scientiarum Biological Sciences, Maringá, v. 28, p. 95-102, 2006. PAIVA, P. D. O.; NAVES, V. C.; DUTRA, L. F.; PAIVA, R.; PASQUAL, M.. In vitro propagation of Nidularium fulgens Lem. Interciência, Caracas, v. 34, p. 593-596, 2009.

PEDROSO, A. N. V.; LAZARINI, R. A. M..; TAMAKI, V.; NIEVOLA, C. C. In vitro culture at low temperature and ex vitro acclimation of Vriesea inflata (Wawra) Wawra an ornamental bromeliad. Revista Brasileira de Botânica, São Paulo, v. 33, p. 407-414, 2010.

PENCE, V. C. The possibilities and challenges of in vitro methods for plant conservation. Kew Bulletin, Kew, v. 65, p. 1-9. 2011.

PEREIRA, E. O.; LIMA, A. B. P.; NOGUEIRA, E. U.; COUTO, D. R.; SOARES, T. C. B. Germinação in vitro de Pitcairnia flammea (Bromeliaceae): efeito do meio de cultivo e do carvão ativo. Enciclopédia Biosfera, Goiânia, v. 7, n. 13, p. 634-642, 2011.

POMPELLI, M.F.; FERNANDES, D.; GUERRA, M.P. Germination of Dyckia encholirioides (Gaudichaud) Mez var. encholirioides under saline conditions. Seed Science \& Techonology, Zurich, v. 34, p. 759-763, 2006.
SANTOS, D. S.; TAMAKI, V.; NIEVOLA, C. C. In vitro propagation of the ornamental bromeliad Acanthostachys strobilacea (Schult. f.) Klotzsch via nodal segments. In Vitro Cellular and Developmental Biology $\square$ Plant, Dordrecht, v. 46, p. 524-529, 2010.

SILVA, A. L. L.; FRANCO, E. T. H.; DORNELLES, E. B.; GESING, J. P. A. Micropropagação de Dyckia maritima Baker Bromeliaceae. Iheringia, Porto Alegre, v. 83, p. 135-138, 2008.

SILVEIRA, D. G.; SOUZA, F. V. D.; PELACANI, C. R.; SOUZA, A. S.; LEDO, C. A. S.; SANTANA, J. R. F. Micropropagation and in vitro conservation of Neoglaziovia variegata (Arr. Cam.) Mez, a fiber producing bromeliad from Brazil. Brazilian Archieves of Biology and Technology, Curitiba, v.52, p. 923-932, 2009.

SUGIYAMA, M. Biomas do Estado de São Paulo. In: BONONI, V. L. R. (Coord.). Biodiversidade. São Paulo: Secretaria de Estado do Meio Ambiente, 2010. p. 31-49.

TAMAKI, V.; DE PAULA, S. M.; NIEVOLA, C. C.; KANASHIRO, S. Soluções nutritivas alternativas para o cultivo de bromélias ornamentais. O Mundo da Saúde, São Paulo, v. 35, p. 91-97, 2011. TAMAKI, V.; MERCIER, H.; NIEVOLA, C. C. Cultivo in vitro de clones de Ananas comosus (L.) Merril cultivar Smooth Cayene em diferentes concentrações de macronutrientes. Hoehnea, São Paulo, v. 34, p. 67-73, 2007.

WANDERLEY, M. G. L.; MARTINS, S. E. Bromeliaceae. In: WANDERLEY, M. G. L.; SHEPHERD, G. J.; MELHEM, T. S.; GIULIETTI, A. M. (Ed.). Flora fanerogâmica do Estado de São Paulo. São Paulo: Imprensa Oficial do Estado de São Paulo, 2007. p. 105.

WIEDENFELD, B. B.; WALLACE, W.; HONS, F. Indicators of cotton nitrogen status. Journal of Plant Nutrition, Philadelphia, v. 32, p. 1353-1370, 2009. 